\title{
Idiopathic Atrial Flutter Associated with Dilated Cardiomyopathy in a Preterm Newborn: A Case Report
}

\author{
Nitin Unde Mahmoud ElHalik Arif Faquih \\ Division of Neonatology, Latifa Women and Children Hospital, Dubai, UAE
}

\section{Keywords}

Atrial flutter - Cardiac dysfunction - Dilated cardiomyopathy . Neonatal intensive care unit $\cdot$ Newborn

\begin{abstract}
Background: Arrhythmias in neonates are uncommon and usually affect newborns with a normal heart or associated with structural heart disease. Meanwhile, one uncommon type of supraventricular arrhythmias is atrial flutter (AF), which is reentry mechanisms in the atrium. The AF may result in heart failure or even death, but the majority of its cases have revealed favorable prognosis in the event of early prenatal diagnosis and immediate treatment [J Am Coll Cardiol. 2006;48:1040-6, Semin Fetal Neonatal Med. 2006;11:182-90, and Arch Argent Pediatr. 2007;105:42735]. A persistent tachyarrhythmia can progress to a state of cardiac dysfunction known as tachycardia-induced cardiomyopathy. While this may be a rare cause of dilated cardiomyopathy and heart failure in children, the condition is usually reversible and should be considered in newborn and infants [Europace. 2011;14(4):466-473]. Case Report: A preterm 33+1-week male newborn with birth weight 2,790 g was delivered through cesarean section. The baby presented with tachycardia after birth associated with respiratory distress. The physical examination showed heart rate $>220 /$ min, and ECG showed "saw tooth pattern" after intravenous
\end{abstract}

adenosine boluses confirming diagnosis of AF (2-3:1). The heart rate reverted to sinus rhythm after synchronized cardioversion. Due to poor LV myocardial performance with dilated chambers, the baby received intravenous milrinone, followed by oral captopril. The baby was discharged on oral medications in perfect clinical condition, and follow-up showed no recurrence AF with improved cardiac function. Conclusion: Despite the rare occurrence, AF should be considered in differential diagnosis of newborn arrhythmia and diagnosed after intravenous adenosine injection. In few cases, AF can be associated with dilated cardiomyopathy which is a reversible condition.

(c) 2021 The Author(s) Published by S. Karger AG, Basel

\section{Background}

Atrial flutter (AF) is an uncommon arrhythmia in newborns and infants. It is a form of supraventricular tachycardia (SVT) characterized by a regular, rapid (atrial rates of 240-360 beats/min) "saw-toothed flutter wave," pattern on the electrocardiograph (ECG). In neonates, 2:1 atrial conduction is common. There are various etiologic factors for AF in newborn. Although it may be asymptomatic, it may even result in severe heart failure requiring urgent therapy [1-3]. Here, we report a case of idiopathic AF in a preterm newborn associated with dilated cardiomyopathy [4].

Correspondence to:

Nitin Unde, drnitinunde @ gmail.com

karger@karger.com www.karger.com/dmj

Karger $\stackrel{\text { ! }}{\text { - }}$

BOPEN ACCESS
(C) 2021 The Author(s)

Published by S. Karger AG, Basel

This is an Open Access article licensed under the Creative Commons Attribution-NonCommercial-4.0 International License (CC BY-NC) (http://www.karger.com/Services/OpenAccessLicense), applicable to the online version of the article only. Usage and distribution for commercial purposes requires written permission. 


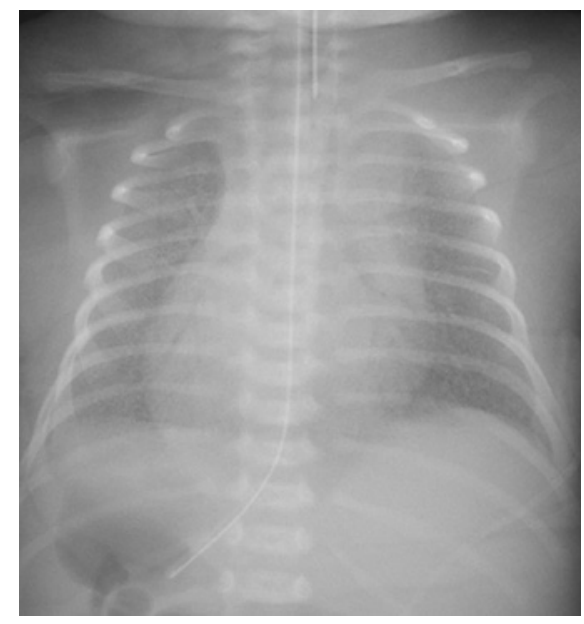

Fig. 1. Chest X-ray on admission.

\section{Case Report}

A male newborn was delivered to a 33-years, G3P0 mother with birth weight $2,790 \mathrm{~g}$. He was born preterm at 33 weeks and admitted in the neonatal intensive care unit for respiratory distress. He was born by emergency caesarean section due to fetal tachycardia with agars 3 and 7 at 1 and $5 \mathrm{~min}$, respectively. His birth weight and head circumference were $2,790 \mathrm{~g}$ and $33.5 \mathrm{~cm}$, respectively. The mother was an unbooked case without any significant antenatal and medical history. There was no history of consanguinity, and family history was noncontributing. At birth, the baby was intubated in view of respiratory distress and later received surfactant with confirmed chest X-ray findings of RDS (shown in Fig. 1). On admission, the baby was euthermic with temperature $36.8^{\circ} \mathrm{C}$, heart rate $>220 / \mathrm{min}$, and $\mathrm{RR}=62 / \mathrm{min}$ with normal 4 limb blood pressure and oxygen saturation. Admission blood gas showed high lactate 4.7 with slightly delayed capillary refill time (4 s). Blood glucose and ionic calcium were normal. A 12-lead ECG was performed which showed narrow complex tachycardia (shown in Fig. 2). Vagal maneuvers - ice pack application over eyeballs - were performed. The baby received 3 doses of intravenous adenosine $(50,100$, and $200 \mu \mathrm{g} / \mathrm{kg} / \mathrm{dose}$ at regular interval), and postadenosine ECG showed a saw tooth pattern confirming typical AF (3:1) (shown in Fig. 3). Due to hemodynamic instability, the baby underwent emergency synchronized DC (direct current) cardioversion $(0.5 \mathrm{~J} / \mathrm{kg})$ with restoration of normal sinus rhythm $(\mathrm{HR}=140 / \mathrm{min}$; BP mean $38 \mathrm{~mm} \mathrm{Hg})$. An echocardiogram done showed a structurally normal heart with compromised LV function (EF 35-40\%) with biventricular dilatation associated with moderate MR and TR. The sepsis screening was negative, and liver and renal function test results were normal.

On day 2, due to recurrence of AF and hemodynamic instability, synchronized DC cardioversion was again performed $(0.5 \mathrm{~J} / \mathrm{kg})$ after administrating sedation. After cardioversion, the sinus rhythm became normal and was started on maintenance dose oral propranolol (1.0 mg/kg/day, 3-4 times a day). The follow-up echocardiography confirmed similar findings as before with compromised LV function (EF 45\%), and hence intravenous milrinone infusion was commenced to improve LV function. Subsequently, milrinone was replaced with oral captopril (max dose $0.3 \mathrm{mg} / \mathrm{kg}$ / dose 3 times daily), and repeat echocardiogram showed improved LV function. The baby was extubated and graded to full feeds. TORCH and parvovirus screening was negative. The baby was discharged on day 15 on oral captopril and furosemide with normal brain ultrasound. Follow-up echocardiograms have continued to show normal biventricular function without any recurrence of AF. Presently, the baby is 6 months old, and there is no further recurrence of AF with normal neurological and cardiac status. The course confirmed diagnosis of idiopathic AF associated with dilated cardiomyopathy.

\section{Discussion}

Our case is a preterm neonate with respiratory distress presented with recurrent episodes of AF which was diagnosed on ECG after the intravenous adenosine. The baby received 2 doses of synchronized DC cardioversion due to AF recurrence in first 3 days of life. The baby also received medications to improve the cardiac functions due to persistent finding of dilated cardiomyopathy on echocardiography. No obvious etiology for AF was found in our case. This is one of the cases with recurrent AF presented in first few days of life associated with dilated cardiomyopathy in a preterm neonate.

Although AF is the second most common tachyarrhythmia in newborn, it is quite uncommon with an overall incidence of $1-2 \%$ [5]. The clinical presentation depends on the overall duration of arrhythmia and can lead to heart failure if left untreated. One of the mechanisms for this atrial re-entry tachycardia is immature myocardium associated with high right atrial pressures during the perinatal period in the fetus and immediate newborn period [6]. Prolonged antenatal fetal tachycardia can lead to hydrops fetalis, deaths, and variable morbidities during the newborn period [1]. The clinical course is determined by initial clinical signs, the duration of $\mathrm{AF}$, and the ventricular response to AF. The present case newborn presented immediately after birth, and the exact duration of fetal tachycardia could not be estimated due to unbooked status of the mother. Asymptomatic tachycardia is the commonest presentation in a newborn noted on routine examination and monitoring. Infants who present beyond 3 months of age are more likely to develop congestive heart failure as per reported studies [1]. The differential diagnosis was SVT which is the most common newborn tachyarrhythmia and initial ECG findings. AF was confirmed on ECG after the administration of intravenous adenosine as it blocks the AV nodes showing typical ECG findings as described in the literature. 
Fig. 2. Twelve-lead electrocardiogram obtained during an episode of tachycardia showed narrow complex tachycardia.
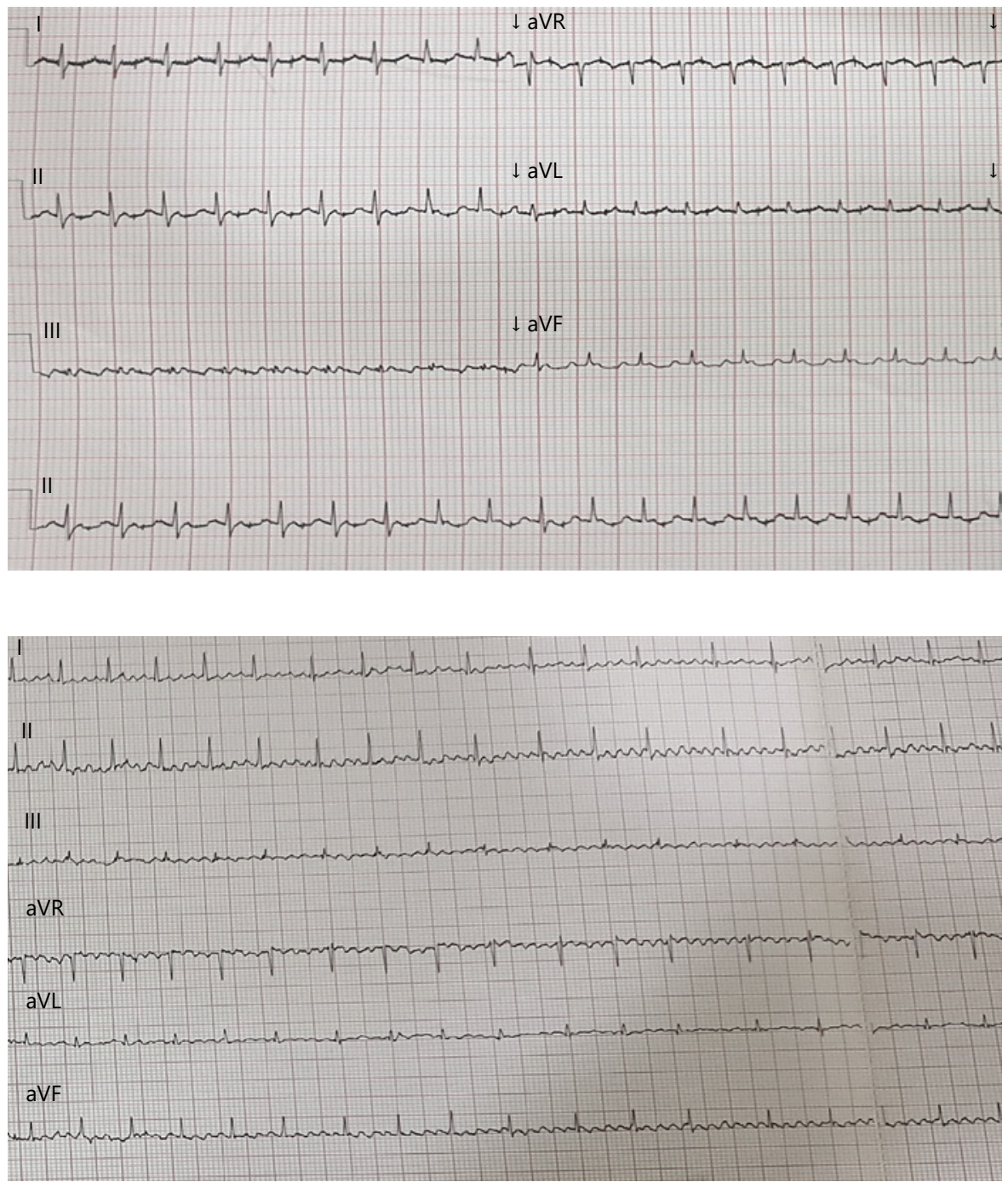

Fig. 3. ECG showing AF. ECG with the presence of typical saw like waves of flutter 2-3:1 (atrial rate 420/bpm; ventricular rate $140 / \mathrm{bpm})$. AF, atrial flutter. cally [7]. In our case, clinical and echocardiography findings justify the electrical cardioversion as the first choice of management. Electrical cardioversion by DC is the most effective method to establish the sinus rhythm in asymptomatic infants as documented by few authors [1]. In other cases, class III antiarrhythmic medications are preferred [8]. Similar to previous studies, we found no association between AF and structural congenital heart disease.

The potential mechanism for the ventricular dysfunction likely had prolonged tachycardia before birth. Obtaining as echocardiogram can be useful to evaluate the ventricular function and to rule out structural heart disease. The presence of additional SVT predicts the recurrence and refractory nature of $\mathrm{AF}[1]$. In our case, the newborn had isolated AF and responded to DC cardioversion without any further recurrence. 
In the present case, AF was associated with dilated cardiomyopathy, sometimes referred to as tachycardiomyopathy, and is a deterioration in ventricular function secondary to incessant tachycardia. This can lead to dilated cardiomyopathy and symptoms of heart failure if unrecognized [4]. Prevalence and incidence of tachycardia-induced cardiomyopathy are difficult to estimate in a preterm newborn due to few published case reports and an underrecognized etiology of dilated cardiomyopathy. Systolic ventricular dysfunction due to an immature myocardium in preterm neonates leads to manifestation of tachycardia-induced cardiomyopathy seen on echocardiogram, followed by left ventricular dilatation after prolonged dysfunction [9], which was quite similar to our case.

In addition, a diagnosis of tachycardia-mediated cardiomyopathy may be difficult to confirm until after normalization or improvement of the ventricular function with control of the tachyarrhythmia. The main approach to treatment of tachycardia-induced cardiomyopathy is control of the tachyarrhythmia. With the elimination of the underlying arrhythmia, the recovery of ventricular function is often seen within days to weeks in infants [10].

Maintenance therapy was provided as per the cardiologist advice which was stopped on follow-up as there was no AF recurrence and resolved ventricular function and dilation, as documented by repeat follow-up echocardiogram. As per the literature, for asymptomatic and uncomplicated AF which responds to electrical cardioversion, maintenance therapy is not necessary $[1,5]$.

\section{Conclusion}

AF is a rare tachycardia in newborn and usually presents in the newborn period as asymptomatic tachycardia. The duration of tachycardia predicts the clinical presen- tation. Isolated AF in a newborn does not suggest an underlying structural heart defect. Infants with AF respond well to DC cardioversion but may convert to sinus rhythm spontaneously. Associated supraventricular arrhythmia increases the risk of recurrence AF. Newborns with AF have an excellent prognosis once in sinus rhythm with low risk of recurrence.

\section{Statement of Ethics}

Written informed consent was obtained from the parents of the patient for publication of the case report and the accompanied images. However, ethical approval was not required in accordance with the Dubai Scientific Research Ethics Committee policies.

\section{Conflict of Interest Statement}

The authors have no conflicts of interest to declare.

\section{Funding Sources}

The authors did not receive any funding.

\section{Author Contributions}

All authors have contributed in preparing and writing this manuscript.

\section{Availability of Data and Material}

All data generated or analyzed during this study are included in this article. Further enquiries can be directed to the corresponding author.

\section{References}

1 Texter KM, Kertesz NJ, Friedman RA, Fenrich AL. Atrial flutter in infants. J Am Coll Cardiol. 2006;48:1040-6.

2 Wren C. Cardiac arrhythmias in the fetus and newborn. Semin Fetal Neonatal Med. 2006; 11:182-90.

3 Kaltenbach G, Pérez S, Vallejo C. Aleteo auricular neonatal. Arch Argent Pediatr. 2007; 105:427-35

4 Simantirakis EN, Koutalas EP, Vardas PE. Arrhythmia- induced cardiomyopathies: the riddle of the chicken and the egg still unanswered? Europace. 2011;14(4):466-73.
5 Lisowski LA, Verheijen PM, Benatar AA, Soyeur DJ, Stoutenbeek P, Brenner JI, et al. Atrial flutter in the perinatal age group: diagnosis, management and outcome. J Am Coll Cardiol. 2000;35:771-7.

6 Wanamaker B, Cascino T, McLaughlin V, Oral H, Latchamsetty R, Siontis KC. Atrial Arrhythmias in pulmonary hypertension: pathogenesis, prognosis and management. $\mathrm{Ar}$ rhythm Electrophysiol Rev. 2018;7(1):43-8.

7 Gulletta S, Rovelli R, Fiori R, Bella PD. Multiple external electrical cardioversions for refractory neonatal atrial flutter. Pediatr Cardiol. 2012;33(2):354-6.
8 Lulic Jurjevic R, Podnar T, Vesel S. Diagnosis, clinical features, management, and post-natal follow-up of fetal tachycardias. Cardiol Young. 2009;19(5):486-93.

9 De Giovanni JV, Dindar A, Griffith MJ, Edgar RA, Silove ED, Stumper O, et al. Recovery pattern of left ventricular dysfunction following radiofrequency ablation of incessant supraventricular tachycardia in infants and children. Heart. 1998;79(6):588-92.

10 Fenelon G, Wijns W, Andries E, Brugada P. Tachycardiomyopathy: mechanisms and clinical implications. Pacing Clin Electrophysiol. 1996;19(1):95-106. 